\title{
Structure, Morphology, and Band Gap of Ti-V-O Mixed Oxides Processed by Coprecipitation and Calcination
}

\author{
M.W. PARK ${ }^{a, *}$, Y.S. $\operatorname{LiM}^{a}$, Y.M. SUNG ${ }^{b}$, D.J. KWAK ${ }^{b}$ AND J.S. LEE ${ }^{a}$ \\ ${ }^{a}$ Department of Materials Engineering, Kyungsung University, Busan, 608-736, Korea \\ ${ }^{b}$ Department of Electrical Engineering, Kyungsung University, Busan, 608-736, Korea
}

\begin{abstract}
Mixed oxides of Ti-V-O were co-precipitated by wet process using $\mathrm{TiCl}_{4}$ and $\mathrm{VOCl}_{3}$ as starting materials. As-precipitated gels were calcinated at $800^{\circ} \mathrm{C}$ for 4 hours in oxygen atmosphere. Effects of vanadium content on the structural evolution, morphology, and band gap of Ti-V-O oxides were investigated. Calcination has produced mixtures of $\mathrm{TiO}_{2} / \mathrm{VO}_{2} / \mathrm{V}_{2} \mathrm{O}_{5}$ oxides and has allowed formation of $\mathrm{Ti}_{1-x} \mathrm{~V}_{x} \mathrm{O}_{2}$. Lattice parameters of rutile $\mathrm{TiO}_{2}$ were precisely measured to investigate vanadium substitution into single rutile phase of $\mathrm{Ti}_{1-x} \mathrm{~V}_{x} \mathrm{O}_{2}$ with varying vanadium content. As vanadium addition was increased, particles were coarsening rapidly during calcination. Band gap of the Ti-V-O oxides was measured using ultraviolet visible light spectrometer. A decrease of band gap down to $1.7 \mathrm{eV}$ with the addition of maximum of 10 at.\% of vanadium was measured, which is due to the formation of single phase of $\mathrm{Ti}_{1-x} \mathrm{~V}_{x} \mathrm{O}_{2}$ as well as the formation of metallic $\mathrm{VO}_{2}$ or $\mathrm{V}_{2} \mathrm{O}_{5}$ particles.
\end{abstract}

DOI: 10.12693/APhysPolA.129.875

PACS/topics: 81.05.Hd

\section{Introduction}

The n-type titanium dioxide $\left(\mathrm{TiO}_{2}\right)$ semiconductor has a wide application in photovoltaics (PV) and photoelectrochemical (PEC) cells, due to its relatively low cost, chemical stability, and photo stability [1-3]. Optical band gap of rutile $\mathrm{TiO}_{2}$ semiconductor is normally of the order of $3.0 \mathrm{eV}$. However, this band gap is too high to effectively utilize the energy of $96 \%$ of solar spectral profile, which is less than $2.0 \mathrm{eV} \mathrm{[4].} \mathrm{To} \mathrm{increase} \mathrm{the} \mathrm{pho-}$ toelectrical efficiency of $\mathrm{TiO}_{2}$, transition metals of $\mathrm{V}, \mathrm{Fe}$, and $\mathrm{W}$ have been doped into the $\mathrm{TiO}_{2}[5,6]$. Phillips et al. [5] have studied the effects of extensive doping of $\mathrm{V}$ in single crystalline $\mathrm{Ti}_{1-x} \mathrm{~V}_{x} \mathrm{O}_{2}(x=0.04-0.55)$ on the variation of the band gap. It was found that the samples of $\mathrm{Ti}_{1-x} \mathrm{~V}_{x} \mathrm{O}_{2}(x=0.3-0.5)$ possess an optical band gap of $1.99 \mathrm{eV}$, which is due to the metallic property of vanadium dioxide [5].

Vanadium addition can result in formation of vanadium oxides, such as $\mathrm{VO}_{2}$ and $\mathrm{V}_{2} \mathrm{O}_{5}$ in the matrix of $\mathrm{TiO}_{2}$. Mixing $\mathrm{VO}_{2}$ and $\mathrm{V}_{2} \mathrm{O}_{5}$ with $\mathrm{TiO}_{2}$ together, with similar positions in their conduction and valence band energies, can increase the spectral range of absorption as well as create type II electronic architecture. This structure can separate and/or localize electron and hole wave functions in the core or shell materials, thereby extending excitation lifetime and photoelectrical efficiency [7]. Since it is possible to increase electron/hole life time by separation of charges, it may be also possible to increase conductivity by electrons and holes through the particles of the $\mathrm{TiO}_{2} / \mathrm{VO}_{2} / \mathrm{V}_{2} \mathrm{O}_{5}$ phases. However, charge separation is significantly dependent on the morphologies of

\footnotetext{
*corresponding author; e-mail: mwpark@ks.ac.kr
}

heterogeneous mixture of $\mathrm{TiO}_{2} / \mathrm{VO}_{2} / \mathrm{V}_{2} \mathrm{O}_{5}$ particles. Either non uniform aggregation of the particles or coarse particle agglomeration are not conducive for the effective application of this heterogeneous structure.

In this work, wet chemical co-precipitation method, using $\mathrm{TiCl}_{4}$ and $\mathrm{VOCl}_{3}$ as starting materials, was used to produce either the single crystalline $\mathrm{Ti}_{1-x} \mathrm{~V}_{x} \mathrm{O}_{2}$ phase or the fine dispersion of nano-sized $\mathrm{VO}_{2}$ and $\mathrm{V}_{2} \mathrm{O}_{5}$ particles in $\mathrm{TiO}_{2}$ matrix. The effects of $\mathrm{V}$ content and calcination conditions on the phase transition, morphology and band gap of the mixed Ti-V-O oxides were studied.

\section{Materials and methods}

\subsection{Materials}

Powder mixtures of vanadium-doped titania were produced by the co-precipitation method starting from $\mathrm{TiCl}_{4}$ (99.9\%, Aldrich Chemical Co.) and $\mathrm{VOCl}_{3}$ (99\%, Aldrich Chemical Co.). Mixed aqueous solutions with various $\mathrm{V} / \mathrm{Ti}$ atomic ratios $(0,1,3,5,8,10$ at.\% of vanadium) were obtained by mixing different aqueous solutions prepared from $\mathrm{TiCl}_{4}$ and $\mathrm{VOCl}_{3}$, respectively. The salts containing the cations were then co-precipitated by adding $\mathrm{NH}_{4} \mathrm{OH}$ (Junsei Chemical Co., $\mathrm{NH}_{3} 28-30 \%$ ) into the mixed aqueous solution. A series of vanadium-doped titania were prepared by changing the $\mathrm{V} /$ Ti ratio. The precipitates were washed with distilled water to remove chloride ions, followed by washing with ethyl alcohol to lighten the agglomeration. The precipitates were cleaned and dispersed in an ultrasonic cleaner under vigorous stirring. They were then vacuum-filtered and dried. Drying was performed at about $120^{\circ} \mathrm{C}$ in a drying oven for 10 hours. The dried powders were then calcined for 4 hours in air at $800^{\circ} \mathrm{C}$. The heating rate was $10^{\circ} \mathrm{C} / \mathrm{min}$.

\subsection{Material characterization}

$\mathrm{X}$-ray diffraction (XRD) technique was employed to identify the phases after calcination. XRD was performed 
on the reacted powders by using a Rigaku D/MAX III diffractometer with Ni-filtered $\mathrm{Cu} \mathrm{K}_{\alpha}$ radiation. Lattice parameters of the rutile $\mathrm{TiO}_{2}$ phase were measured precisely with the high angle diffraction patterns at over $60^{\circ}$ of $2 \theta$ using least squares method. Scanning electron microscope (SEM, HITACHI, S-2400) was used to characterize the particle morphology of the as-calcined precipitates with various vanadium additions. Band gap energy of the Ti-V-O oxides was measured by Ultraviolet-visible spectrophotometer (UV-Vis, JASCO (Japan) V-670).

\section{Results and discussion}

The effects of vanadium content and calcination conditions on the phase evolution in Ti-V-O mixed oxides were studied by XRD. Figures $1 \mathrm{a}$ and $1 \mathrm{~b}$ show XRD patterns obtained from the Ti-V-O specimens with different $\mathrm{V}$ contents, calcined at $800^{\circ} \mathrm{C}$ for 4 hours in oxygen atmosphere. It is clearly seen that the increasing vanadium addition over 5 at.\%, as shown in Fig. 1b, resulted in the promotion of rutile $\mathrm{TiO}_{2}$ phase transition from the metastable anatase phase, which was present in XRD diagram in Fig. 1a. However, the phases of $\mathrm{VO}_{2}$ and $\mathrm{V}_{2} \mathrm{O}_{5}$ were not identified in both Figures. It may be due to the much smaller amount (less than 10 at.\%) of vanadium addition compared to titanium content. In our previous report of thermogravimetric analysis (TG) and differential thermal analysis (DTA) [8], the reduction from $\mathrm{V}^{5+}$ to $\mathrm{V}^{4+}$ was observed on DTA curves of the V-rich samples below $800^{\circ} \mathrm{C}$. This may provide information about the location of vanadium. The $\mathrm{V}^{5+}$ may exist as the small particle in the form of $\mathrm{V}_{2} \mathrm{O}_{5}$ homogeneously dispersed within the matrix of $\mathrm{TiO}_{2}$ particles, while $\mathrm{V}^{4+}$ is possible in the octahedral lattice of $\mathrm{TiO}_{2}$, as well as in the form particles of $\mathrm{VO}_{2}$ dispersed within the of $\mathrm{TiO}_{2}$ crystal. Thus, a portion of vanadium ions can be incorporated at $800^{\circ} \mathrm{C}$ into $\mathrm{TiO}_{2}$ lattice, substituting for $\mathrm{Ti}$ in single phase of $\mathrm{Ti}_{1-x} \mathrm{~V}_{x} \mathrm{O}_{2}$.
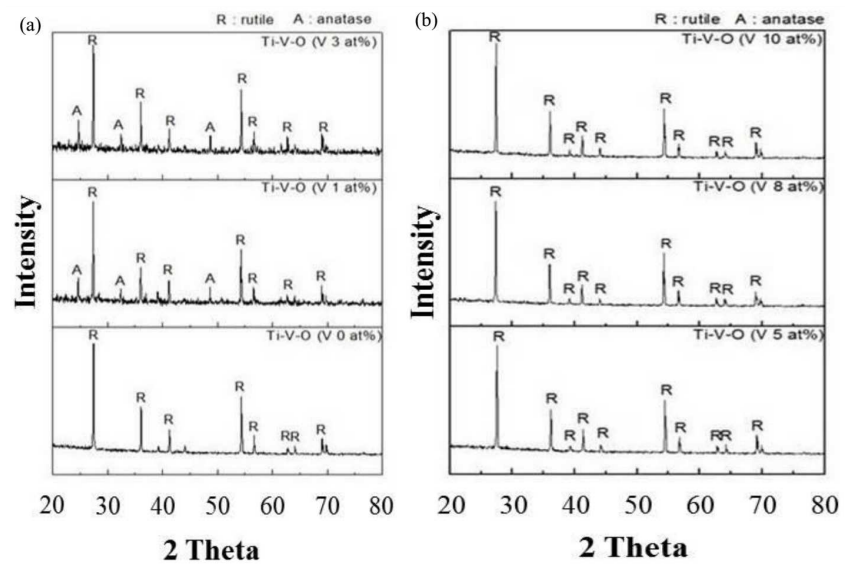

Fig. 1. X-ray diffraction patterns of the copreciptated particles with different vanadium additions after calcination at $800^{\circ} \mathrm{C}$ for 4 hours in air. (a) anatase phase is present up to 3 at.\% of vanadium addition, (b) no anatase phase is identified over 5 at.\% of vanadium addition.
Precise lattice parameters of the rutile $\mathrm{Ti}_{1-x} \mathrm{~V}_{x} \mathrm{O}_{2}$ phase were calculated from the patterns obtained at high angle diffraction with the $2 \theta>60^{\circ}$, using the least squares method. Table I shows the calculated lattice parameters of the rutile $\mathrm{Ti}_{1-x} \mathrm{~V}_{x} \mathrm{O}_{2}$ ( $x$ is not known) phases, calcinated at $800^{\circ} \mathrm{C}$ in air, with varying amount of vanadium content. Both of $a$ and $c$ parameters do not significantly change as the vanadium addition is being increased.

TABLE I

Lattice constants measured from the XRD patters of the rutile $\mathrm{TiO}_{2}$ phase (calcination at $800^{\circ} \mathrm{C}$ in air), assuming formation of $\mathrm{Ti}_{1-x} \mathrm{~V}_{x} \mathrm{O}_{2}$ powders. ${ }^{*}$ - lattice constant of rutile $\mathrm{TiO}_{2}: a=0.45933 \mathrm{~nm}, c=0.29592 \mathrm{~nm}$ (ref. JCPDS file \# 21-1276).

\begin{tabular}{c|c|c}
\hline \hline $\begin{array}{c}\text { Vanadium } \\
\text { [at.\%] }\end{array}$ & \multicolumn{2}{|c}{ Lattice constant [nm] } \\
\cline { 2 - 3 } & $a$ & $c$ \\
\hline 1 & 0.45649 & 0.29023 \\
3 & 0.45684 & 0.28939 \\
5 & 0.45612 & 0.29105 \\
8 & 0.45608 & 0.29066 \\
10 & 0.45649 & 0.29096
\end{tabular}

Stable phase of either $\mathrm{TiO}_{2}$ or $\mathrm{VO}_{2}$ is the rutile phase at high temperature of $800^{\circ} \mathrm{C}$. Thus it may be relevant for $\mathrm{V}$ ions in a form of $\mathrm{V}^{+4}$ being able to substitute $\mathrm{Ti}$ ions in the similar rutile phase. When the coordination number of $\mathrm{Ti}$ ion is 6 , the ionic radius of $\mathrm{Ti}^{+4}$ is $74.5 \mathrm{pm}$ whereas it is $72 \mathrm{pm}$ for the $\mathrm{V}^{+4}$. It may indicate that as $\mathrm{V}$ content increases in the rutile $\mathrm{Ti}_{1-x} \mathrm{~V}_{x} \mathrm{O}_{2}$ phase, the lattice constant can be decreasing. However, in Table I, there is little change in lattice constants for $a$ and $c$ with the increase of vanadium content. This can be attributed to the fact that a very small amount of vanadium is substituting for $\mathrm{Ti}$ in all the specimens. Thus, it is possible that vanadium may exit in the form of $\mathrm{VO}_{2}$ and $\mathrm{V}_{2} \mathrm{O}_{5}$ phases.

TABLE II

Band gap energies of the coprecipitated Ti-V-O mixed particles after calcination.

\begin{tabular}{c|c}
\hline \hline Vanadium [at.\%] & Band gap energy [eV] \\
\hline 0 & 3.0 \\
1 & 2.8 \\
3 & 2.1 \\
5 & 2.2 \\
8 & 2.1 \\
10 & 1.7
\end{tabular}

Figures $2 \mathrm{a}-2 \mathrm{e}$ show the UV-Vis spectra of the coprecipitated Ti-V-O mixed particles after calcination. Asmeasured band gap energies of the calcinated $\mathrm{Ti}_{1-x} \mathrm{~V}_{x} \mathrm{O}_{2}$ phases are shown in Table II. The spectra were recorded in absorbance vs. wavelength ranging from 200 to $800 \mathrm{~nm}$. The spectral data in Fig. 2a shows a cut off at $444 \mathrm{~nm}$ corresponding to the band gap of $2.8 \mathrm{eV}$, as measured by direct extrapolation of absorption spectrum. 

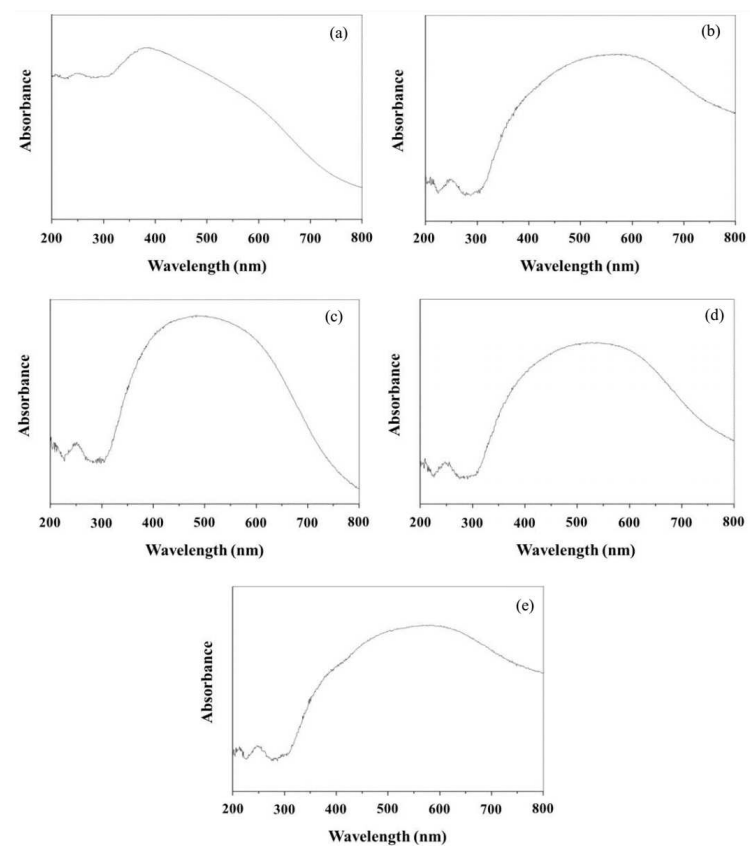

Fig. 2. UV-Vis spectrum of the coprecipitated Ti-V$\mathrm{O}$ mixed particles. Vanadium doping contents are (a) 1. at\%, (b) 3 at.\%, (c) 5 at. \%, (d) 8 at. $\%$, and (e) 10 at.\%.

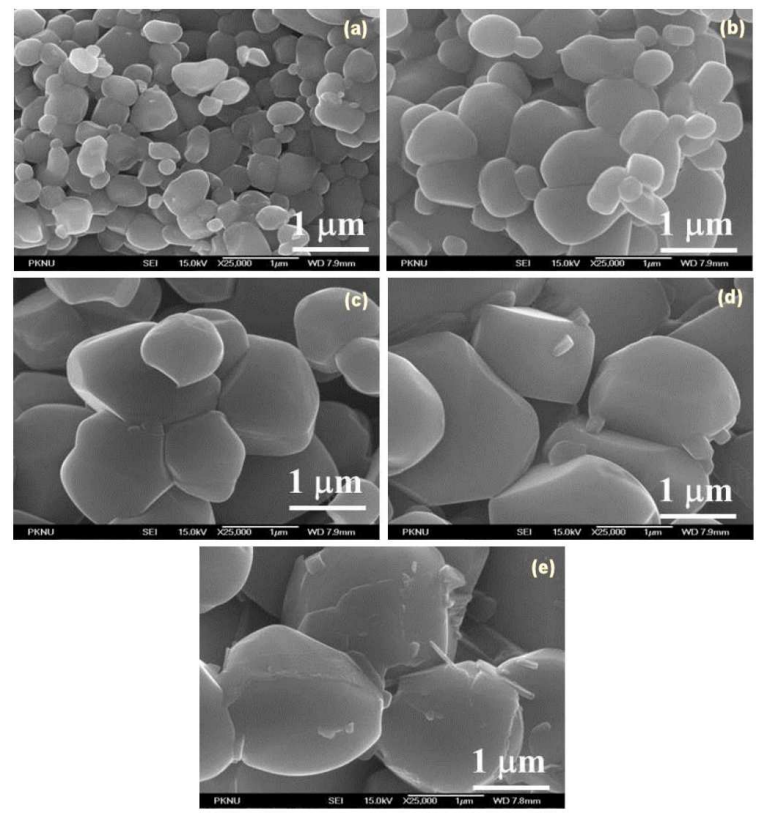

Fig. 3. EM micrographs of mixed Ti-V-O powders (calcinated at $800^{\circ} \mathrm{C}$ in air). Vanadium doping contents are (a) 1 at.\%, (b) 3 at.\%, (c) 5 at.\%, (d) 8 at.\%, and (e) 10 at.\%.
The cut off wavelength increases up to $730 \mathrm{~nm}$ (band gap of $1.7 \mathrm{eV}$ ) in Fig. 2e. Although some scattering in band gap energies is visible in Table II, in general the band gap decreases from $2.8 \mathrm{eV}$ to $1.7 \mathrm{eV}$ as the vanadium content increases.

SEM micrographs of Figs. 3a-3e show the size and morphology of the specimens with different amounts of $\mathrm{V}$ addition in $\mathrm{TiO}_{2}$ matrix. These micrographs were all taken at the same magnification. The maximum size of Ti-V-O particles ( 1 at. $\%$ of vanadium addition) is less than roughly $1 \mu \mathrm{m}$ as shown in Fig. 3a. However, the maximum particle size increases much over $1 \mu \mathrm{m}$ as vanadium addition increases (Figs. $3 \mathrm{~b}-3 \mathrm{e}$ ). This may be due to the differences of the physical properties such as melting temperature between the $\mathrm{TiO}_{2}, \mathrm{VO}_{2}$, and $\mathrm{V}_{2} \mathrm{O}_{5}$ particles (melting points of 1843,1967 and $690^{\circ} \mathrm{C}$, respectively).

\section{Conclusions}

Mixed oxides of $\mathrm{Ti}_{1-x} \mathrm{~V}_{x} \mathrm{O}_{2}, \mathrm{VO}_{2}$, and $\mathrm{V}_{2} \mathrm{O}_{5}$ particles were produced by coprecipitation method starting from $\mathrm{TiCl}_{4}$ and $\mathrm{VOCl}_{3}$. Various $\mathrm{V} / \mathrm{Ti}$ atomic ratios $(0,1,3$, $5,8,10$ at.\% of vanadium) were studied to investigate structural evolution, morphology and band gap of the mixed oxides particles. The mixtures of coprecipitated oxides were calcined for 4 hours at $800^{\circ} \mathrm{C}$ in oxygen atmosphere. Vanadium is found in the form of $\mathrm{V}^{4+}$ and $\mathrm{V}^{5+}$ cations in the as-calcined particles of $\mathrm{Ti}_{1-x} \mathrm{~V}_{x} \mathrm{O}_{2}, \mathrm{VO}_{2}$, and $\mathrm{V}_{2} \mathrm{O}_{5}$. As the vanadium content increases, band gap of the $\mathrm{Ti}_{1-x} \mathrm{~V}_{x} \mathrm{O}_{2}$ decreases from $3.0 \mathrm{eV}$ to $1.7 \mathrm{eV}$, due to the vanadium substitution for titanium in titanium dioxide particles.

\section{References}

[1] K.I. Hadjiivanov, D.K. Klissurski Chem. Soc. Rev. 25, 61 (1996).

[2] A. Heller, Acc. Chem. Res. 28, 503 (1995).

[3] M.W. Park, K.Y. Chun, Electron. Mater. Lett. 5, 7 (2009).

[4] A.J. Nozik, Ann. Rev. Phys. Chem. 29, 189 (1978).

[5] T.E. Phillips, K. Moorjani, J.C. Murphy, T.O. Poehler, J. Electrochem. Soc. 129, 1210 (1982).

[6] G.K. Mor, H.E. Prakasam, O.K. Varghese, K. Shankar, C.A. Grimes, Nano Lett. 7, 2356 (2007).

[7] S. Somasundaram, N. Tacconi, C.R. Chenthamarakshan, K. Rajeshwar, J. Electroanal. Chem. 577, 167 (2005).

[8] M.-W. Park, H.-J. Kwon, J.-S. Lee, J.-C. Park, J.-H. Kim, C.-G. Kim, Electron. Mater. Lett. 7, 327, (2011). 